After leaving hospital many patients turn to one of the many voluntary self help groups or cancer support centres. Most of these groups offer simple social support, counselling, and some forms of complementary medicine. These may include sessions of relaxation and meditation, either in a group or individually with a healer, and an introduction to the Simonton technique of visualising images designed to promote healing and recovery. ${ }^{67}$ Simple nutritional advice recommending vegetarian food is usually also given. Few groups have an attending doctor, and all work outside the conventional routes of medical referral.

These centres and support groups seldom have any defined link with the National Health Service, and all are self financing. ${ }^{8}$ They do not see themselves as offering cures for cancer but aim at supporting anxious people at a time of crisis, disclosing and strengthening their inner resources, and pointing the way to self help-complementing rather than conflicting with conventional cancer treatment. Their patients are grateful for help given in a sympathetic and unhurried atmosphere, which is rarely achieved in a hospital setting. Some report that the insight they gain has favourably transformed their view of themselves and their role in life, irrespective of the outcome of the cancer treatment.

Realisation of the need for psychological support has led to some oncology clinics including a cancer counsellor or psychotherapist, a professional who has had special training in the psychological problems and communication difficulties that arise with cancer. ${ }^{9-13}$ We suggest a natural extension of this: oncology clinics should set up their own cancer support group, run as a day centre in or near the hospital for those who need it, with counsellors and other staff working both in the hospital and in the group. Contacts made initially with patients in the wards or clinics could be continued as necessary afterwards. Additional services offered could be those of a social worker, chaplain, art therapist, and visiting doctors, as well as those provided by voluntary assistants.

The style of accommodation for such a support centre is important. It should avoid a hospital atmosphere and be informal, comfortable, and welcoming. At least one room should be big enough for group meetings, with other smaller rooms for individual consultations. There should be a kitchen, toilet facilities, and easy access for unwell or disabled patients.

Of course there are some extremists in complementary medicine who claim miracle cures based on anecdote and not on rigorous clinical trial. Such people are as damaging as those doctors who think that their relationship with a patient is threatened by sharing it with a colleague outside conventional medicine. But if the patient benefits - why not?

Such an organisation would cost money, but this would be only a small proportion of the total cost of cancer treatment. Overcoming the present hiatus between hospital and voluntary support services, it would recognise and integrate the role of support groups, permitting a much needed appraisal of their complementary methods. If the culture of the new National Health Service really will be more flexible then support services for cancer patients and others stand a good chance of success.

Consultant Physician

JOHN COSH

Cancer Help Centre,

Clifton,

Bristol BS8 4PG

Professor of Clinical Oncology,

KAROL SIKORA

Royal Postgraduate Medical School,

London W12 0HS
Sikora K, Waxman JH. New therapeutic strategies in oncology. In: Dawson AM, Besser GM, ed. Recent advances in medicine. Vol 20. Edinburgh: Churchill Livingstone, 1988:53-68.

Watson $M$. Greer S, ed. Psychological issues in malignant disease. Oxford: Pergamon Press, 1986.

3 Fallowfield LJ, Baum M. Psychological welfare of patients with breast cancer. $\mathcal{J} R$ Soc Med 1989;82:4-5.

+ Derogatis LR, Morrow GR, Fetting J, et al. The prevalence of psychiatric disorders among cancer patients. FAMA 1983;249:751-7.

5 Slevin ML, Terry Y, Hallett N, et al. BACUP-the first two vears: evaluation of a national cancer information service. Br Med f 1988;297:669-72.

6 Simonton OC, Matthews-Simonton S, Creighton J. Getting well again. A step-by-step, self-help guide to overcoming cancer for patients and their families. Los Angeles: J Tarcher, 1978.

Bridge LR, Benson P, Pietroni PC, Priest RG. Relaxation and imagery in the treatment of breast cancer. Br Med f 1988;297:1169-72.

8 Black ME. Self help groups and professionals-what is the relationship? Br Med $\mathcal{F}$ 1988;296: $1485-6$.

9 Fallowfield LJ. Counselling for patients with cancer. Br Med f 1988;297:727-8.

10 Fallowfield LJ, Baum M, Maguire GP. Addressing the psychological needs of the conservatively treated breast cancer patient: discussion paper. $7 R$ Soc Med 1987;80:696-9.

11 Ramirez AJ. Liaison psychiatry in a breast cancer unit. $7 R$ Soc Med 1989;82:15-7.

12 Maguire P, Faulkner A. How to do it: communicate with cancer patients: 1 Handling bad news and difficult questions. Br Med f 1988;297:907-9.

13 Maguire P, Faulkner A. How to do it: communicate with cancer patients: 2 Handling uncertainty, collusion, and denial. Br Med f 1988;297:972-4.

\section{A unique opportunity to upgrade genitourinary medicine}

\section{Doctors must join ministers in pushing for better services}

In a recent parliamentary debate on AIDS the Health Minister, Mr David Mellor, identified genitourinary medicine as a cinderella service, thus recognising what many have long known. ' The health service for venereal diseases was created in 1916 because of a major public health problem,,$^{2}$ but since then development of the specialty has been inadequate. As recently as the late 1970 s half of the 189 genitourinary medicine clinics in England and Wales were open for 10 hours or less each week, some health districts (as now) had no service at all, while some doctors in the clinics were using inappropriate approaches to diagnosis and treatment. ${ }^{3}$ This audit was one of the elements that helped the specialty to put its house in order. In addition, the specialist advisory committee in genitourinary medicine of the Joint Committee on Higher Medical Training has dragged the specialty towards the twentieth century by making it accept entry criteria and training programmes equivalent to those for all the other medical specialties.

Despite these internal efforts much has happened externally to put impossible pressures on those working in clinics. Over the decade 1976-86 the number of new cases seen in all genitourinary clinics in the United Kingdom has risen by two thirds from 418623 to 702223 , increases in all regions in England varying from $20 \%$ to $120 \%$. Staff have, however, increased over the same period by only $15 \% .+A$ survey by the committee on genitourinary medicine of the Royal College of Physicians has shown that an $80 \%$ shortfall in consultant posts has occurred in England and Wales and that posts would need to be increased from 128 to 233 over 10 years to rectify this, which would require creating 12 additional senior registrar posts. ${ }^{5}$ The Joint Planning Advisory Committee, which is responsible for supervising medical manpower, has not accepted this increase as it will use only the plans for consultant expansion given to it by the regions and the Department of Health. Unfortunately, most regions have not thought about the issue of manpower in genitourinary medicine and have minimal plans or no plans for expansion. Thus at the time of the committee's review of genitourinary medicine in 1988 the regions in England and Wales had plans 
to create half the number of posts considered necessary by the Royal College of Physicians. This catch 22 situation must be broken through rapidly.

Rapid expansion is essential as not only has the workload increased but also the specialty is in the forefront of the epidemic of HIV infection. Most HIV infection in Britain is still acquired through sexual transmission. Departments of genitourinary medicine are vital to the effective control of the infection: they must offer open access self referral services for testing and health education for individual patients. Homosexual men have indicated that the information that has allowed them to alter their behaviour has come from clinics and gay voluntary organisations and not the government. ${ }^{6}$ The government's original campaign on AIDS created anxiety in the general population, causing people to come to clinics for counselling and testing, although they were not at risk. ${ }^{7}$ The clinics must continue to give advice and care to those at high and low risk, but all this entails overwork and delays. A personal view in this journal evocatively described the difficulties of one patient in obtaining care in a series of departments of genitourinary medicine ${ }^{8}$ and prompted the chief medical officer to write to all regional general managers in July 1986, recommending that a patient should be seen on the day of presentation or on the next occasion the clinic was open. This was followed later in the year by a letter from the Secretary of State to all district health authority chairmen, drawing their attention to the pressures being placed on departments of genitourinary medicine and emphasising the need for these clinics to be provided with additional resources. Sadly, nothing happened.

Now a Department of Health working group has reported after visiting a $10 \%$ sample of the clinics in England. ${ }^{9}$ It identified again the increase in workload and the inadequate accommodation, which was judged to be poor in three quarters of the clinics. "Already stretched services are being pressurised still further by poor accommodation which results in a waste of staff time and poor patient flow." Often patients had to wait in corridors adjacent to examination rooms so that only "lip service can be paid to the principle of confidentiality." The group confirmed inadequate medical, nursing, health advisory, and clerical staffing. In some instances the delays for appointments were up to two weeks, which is unacceptable for acute infectious diseases. The unanimous view of the group was that the genitourinary medicine service was ill equipped to deal with the demand placed on it. Making 36 recommendations for improvement, the group reached the overall conclusion that "genitourinary medicine should be designated as a priority and additional resources should be made available to implement the team's recommendations. Hitherto exhortation has failed to lead to the improvements intended by the Department of Health. It is therefore vital that ministers and the NHS management board should give a lead in developing this part of the NHS."

Mr David Mellor has accepted the report and last month wrote to all regional health authorities indicating that the resources available to health authorities to fight AIDS would be doubled in the next financial year (1989-90) to $£ 130 \mathrm{~m}$. He hoped that genitourinary medicine would be substantially upgraded as "these services have been neglected in too many places for too long, yet they are crucial in stopping the spread of HIV."

This push is welcome, but there is a long way to go. Given the previous lack of response by regions and districts doctors must argue for the resources to be used as intended. Genitourinary physicians have not always been good advocates of their cause, but they now have a unique opportunity through AIDS, the Department of Health report, and additional money to create a first class modern service. They must persuade the regions of their case. If regions have done little many of them are also under suspicion of delaying the allocation of earmarked AIDS money to districts until late in the financial year, when it is of limited use, and of funding the general regional overspend from this special money. Doctors need to be persuasive and even argumentative if genitourinary medicine is not to be pushed aside yet again.

Professor of Genitourinary Medicine,

MICHAEL W ADLER

Academic Department of Genitourinary Medicine,

University College and Middlesex School of Medicine,

London W1N 8AA

1 Mellor D. House of Commons Parliamentary Debales (Hansard) 1989 January 13;144:cols 1099-161. (No 27.)

2 Adler MW. The terrible peril: a historical perspective on the venereal diseases. Br Med $\mathrm{J}$ 1980;280:206-11.

3 Adler MW, Belsey EM, O'Connor BH, Catterall RD, Miller DL. Facilities and diagnostic criteria in sexually transmitted disease clinics in England and Wales. British fournal of Venereal Diseases sexually transm
$1978 ; 54: 2-9$.

4 Department of Health and Social Services. New cases seen at NHS genitourinary medicine climics in England in 1976-1986. London: DHSS, 1988. (Statistical Bulletin.)

5 Committee on Genitourinary Medicine. Future manporver requirements and maintenance of standards of clinical care in departments of genitourinary medicine. London: Royal College of Physicians, 1986.

6 Carne CA, Weller IVD, Johnson AM, et al. Prevalence of antibodies to human immunodeficiency virus, gonorrhoea rates and changed sexual behaviour in homosexual men in London. Lancet 1987; ;i:656-8.

7 Sonnex C, Petherick A, Adler MW, Miller D. HIV infection: increase in public awareness and anxiety. Br Med f 1987;295: 193-5.

8 Anonymous. Personal view. Br Med f 1986;292:1735.

9 Department of Health. Report of the working group to examine workloads in genitourinary medicine clinics. London: Department of Health, 1988. 